\title{
A Small Wideband Microstrip-fed Monopole Antenna
}

\author{
Jihak Jung, Wooyoung Choi, and Jaehoon Choi, Member, IEEE
}

\begin{abstract}
A small microstip-fed monopole antenna, which consists of a rectangular patch and a truncated ground plane, is presented for ultra wideband application. The proposed antenna is designed to operate over 3.1 to $11 \mathrm{GHz}$ for $S_{11}<-10 \mathrm{~dB}$. Good return loss and radiation pattern characteristics are obtained in the frequency band of interest.
\end{abstract}

Index Terms-Monopole antennas, truncated ground plane, ultra wideband (UWB).

\section{INTRODUCTION}

$\mathbf{N}$ OWADAYS, wireless communication systems are becoming increasingly popular. However, the technologies for wireless communication still need to be improved further to satisfy the higher resolution and data rate requirements. That is why ultra wideband (UWB) communication systems covering from $3.1 \mathrm{GHz}$ to $10.6 \mathrm{GHz}$ released by the FCC in 2002 [1] are currently under development. For many years, various antennas for wideband operation have been studied for communications and radar systems [2], [3]. The design of wideband antenna is very difficult task especially for hand-held terminal since the compromise between size, cost, and simplicity has to be achieved. In UWB communication systems, one of key issues is the design of a compact antenna while providing wideband characteristic over the whole operating band. Due to their appealing features of wide bandwidth, simple structure, omnidirectional radiation pattern, and ease of construction several wideband monopole configurations, such as circular, square, elliptical, pentagonal, and hexagonal have been proposed for UWB applications [4]-[6]. However, they are not suitable for integration with printed circuit boards since they do not have planar structures. Thus, a microstrip-fed monopole antenna is suitable candidate for integration with hand-held terminal owing to its attractive features such as low profile, low cost, and light weight.

In this letter, we present a novel compact ultra wideband microstip-fed printed monopole antenna. To achieve the maximum impedance bandwidth, a pair of notches is placed at the two lower corners of the patch and the notch structure is embedded in the truncated ground plane. Simulated and experimental results are presented to demonstrate the performance of a suggested antenna.

Manuscript received April 5, 2005; revised June 13, 2005. This work was supported by the HY-SDR Research Center, Hanyang University, under the ITRC Program of IITA. The review of this letter was arranged by Associate Editor J.-G. Ma.

The authors are with the Department of Electronics and Computer Engineering, Hanyang University, Seoul 133-791, Korea (e-mail: jhjung7601@ empal.com; choijh@ @anyang.ac.kr).

Digital Object Identifier 10.1109/LMWC.2005.856834

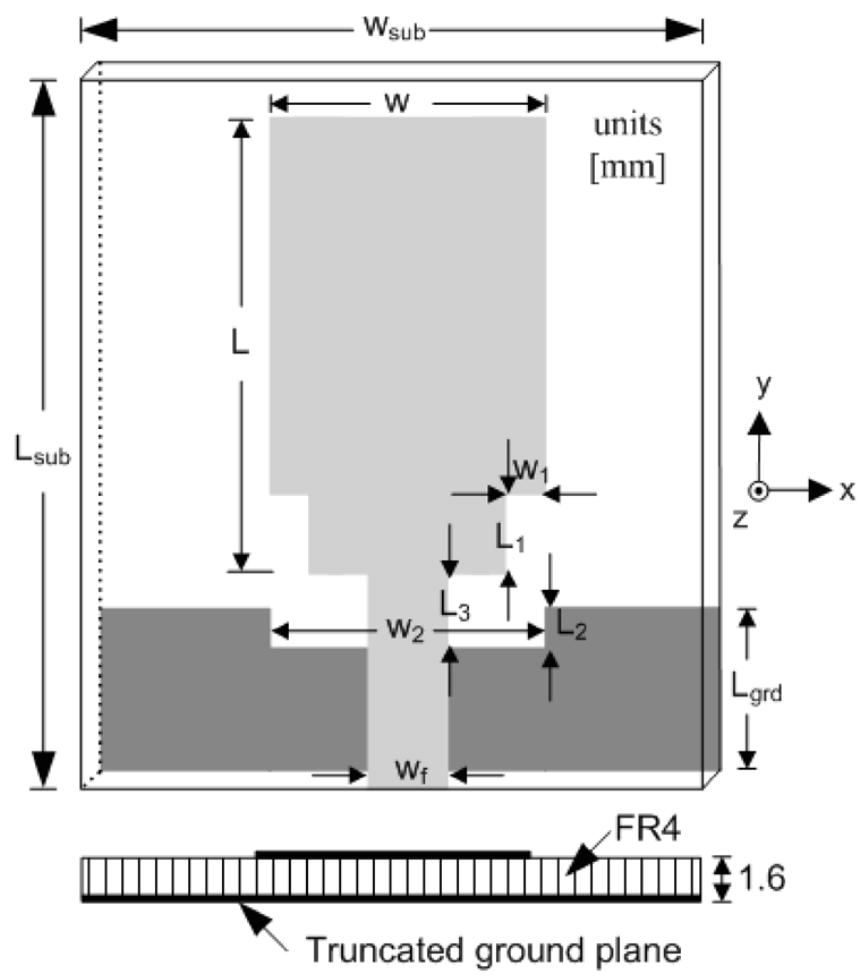

Fig. 1. Configuration of the proposed microstrip-fed monopole antenna.

\section{ANTENNA DESIGN}

Fig. 1 shows the configuration of the proposed wideband antenna which consists of a rectangular patch with two notches at the two lower corners of the rectangular patch and a truncated ground plane with the notch structure.

The proposed antenna, which has compact dimension of $16 \mathrm{~mm} \times 18 \mathrm{~mm}\left(W_{\mathrm{sub}} \times L_{\mathrm{sub}}\right)$, is constructed on FR4 substrate with thickness of $1.6 \mathrm{~mm}$ and relative dielectric constant of 4.4. The width $W_{f}$ of the microstrip feedline is fixed at $2 \mathrm{~mm}$. On the front surface of the substrate, a rectangular patch with size of $W \times L$ is printed. The rectangular patch has a distance of $L_{3}$ to the ground plane printed on the back surface of the substrate. By cutting the two notches of suitable dimensions $\left(W_{1} \times L_{1}\right)$ at the monopole's two lower corners, it is found that much enhanced impedance bandwidth can be achieved for the proposed antenna. This phenomenon occurs because the two notches affect the electromagnetic coupling between the rectangular patch and the ground plane [7]. In addition, to achieve good wideband matching of the proposed antenna, the separation $L_{3}$ between the rectangular patch and the notch in the ground plane is used. The modified truncated ground plane acts as an impedance matching element to control the impedance bandwidth of a square monopole [8]. The dimension of the notch $\left(W_{2} \times L_{2}\right)$ embedded in the truncated ground 


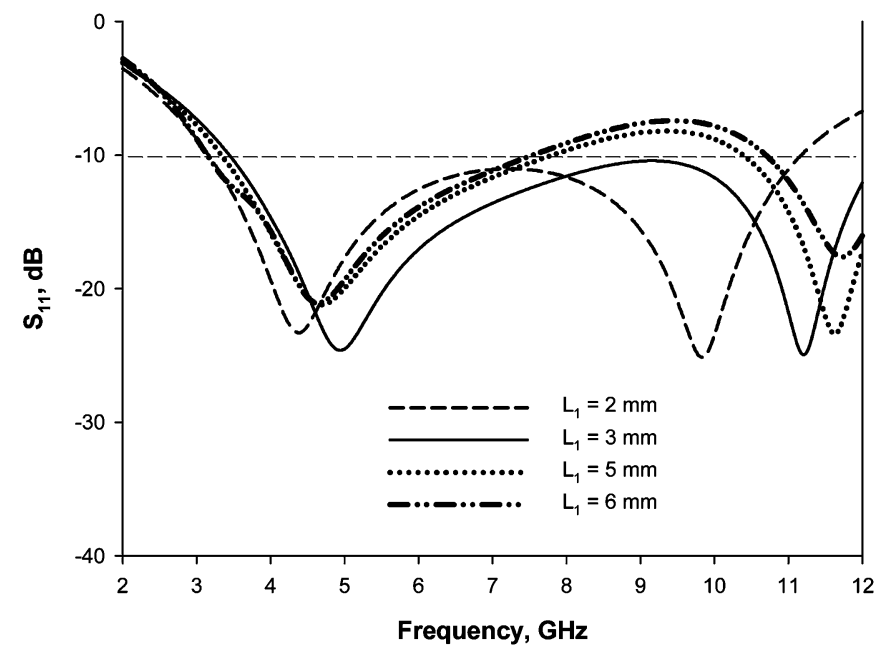

Fig. 2. Simulated return loss for various $L_{1}$ at the two lower corners of the proposed monopole antenna. ( $W_{1}$ is fixed at $1 \mathrm{~mm}$ ).

plane and feed gap distance $L_{3}$ are important parameters in determining the sensitivity of impedance matching.

The optimal dimensions of the designed antenna are as follows: $W_{\text {sub }}=16 \mathrm{~mm}, L_{\text {sub }}=18 \mathrm{~mm}, W=7 \mathrm{~mm}, L=11 \mathrm{~mm}$, $W_{1}=1 \mathrm{~mm}, L_{1}=2 \mathrm{~mm}, W_{2}=7 \mathrm{~mm}, L_{2}=1 \mathrm{~mm}, L_{3}=$ $3 \mathrm{~mm}, W_{f}=2 \mathrm{~mm}$, and $L_{\text {grd }}=4 \mathrm{~mm}$. It is found that the designed antenna satisfies all the requirements in UWB frequency band ranging $3.1 \mathrm{GHz}$ to $11 \mathrm{GHz}$. The size of the designed antenna is much smaller than the UWB antennas reported recently.

\section{RESUlTS AND DiscusSIONS}

The microstip-fed monopole antennas with various parameters $\left(L_{1}, L_{2}\right.$, and $\left.W_{2}\right)$ were constructed and studied to demonstrate the proposed bandwidth-enhancement technique. The simulated results are obtained using the Ansoft simulation software high-frequency structure simulator (HFSS) [9]. Fig. 2 shows the simulated return loss curves for various notch sizes $\left(W_{1} \times L_{1}\right)$. As the notch sizes $\left(W_{1} \times L_{1}\right)$ are changed from $1 \times 6$ to $1 \mathrm{~mm} \times 2 \mathrm{~mm}$, the impedance bandwidth becomes greater than $4 \mathrm{GHz}$, with decrease of the upper frequency $f_{U}$. It is also observed that the upper frequency $f_{U}$ is significantly affected by the variation in notch length $L_{1}$. On the other hand, the lower frequency $f_{L}$ is insensitive to the change of $L_{1}$.

The simulated return loss curves with different values of $L_{2}$ are plotted in Fig. 3 when $W_{2}$ is fixed at $6 \mathrm{~mm}$. From the simulation results in Fig. 3, it is found that the $10 \mathrm{~dB}$ impedance bandwidth decreases as the notch length $L_{2}$ increases. The optimized notch length $L_{2}$ on the truncated ground plane is $1 \mathrm{~mm}$. The simulated return loss curves with the optimal notch length $L_{2}$ for various notch widths $W_{2}$ on the truncated ground plane are plotted in Fig. 4. As the notch width $W_{2}$ increases, the lower frequency $f_{L}$ is slightly lowered and the upper frequency $f_{U}$ is markedly increased. It is observed that the notch width $W_{2}$ is the most critical parameter to determine the upper frequency $f_{U}$. The notch width $W_{2}$ is chosen as $7 \mathrm{~mm}$ to yield near optimal bandwidth.

Fig. 5 shows measured and simulated return loss characteristics of the proposed antenna. Measured impedance bandwidth is wider than simulated one in Fig. 5. The fabricated antenna

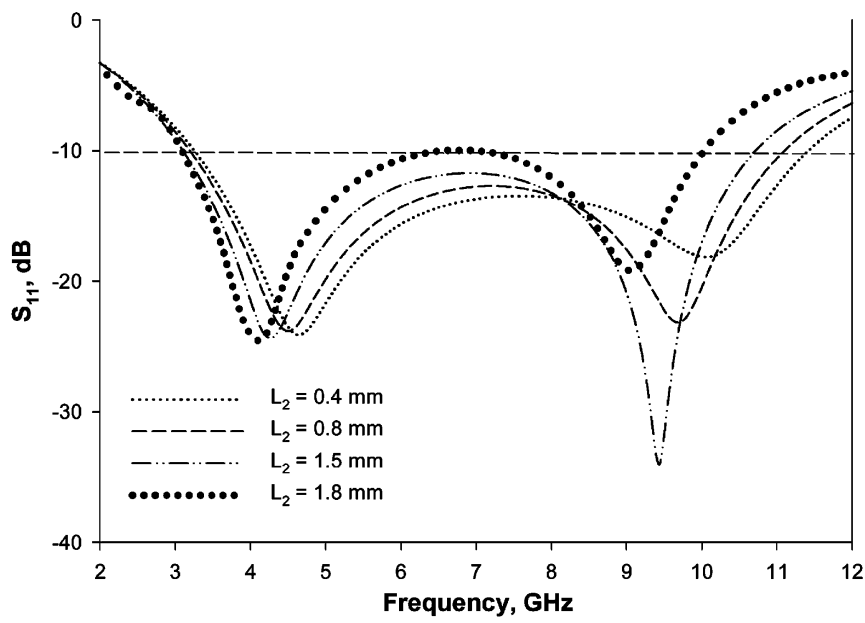

Fig. 3. Simulated return loss for various $L_{2}$ on the truncated ground plane.

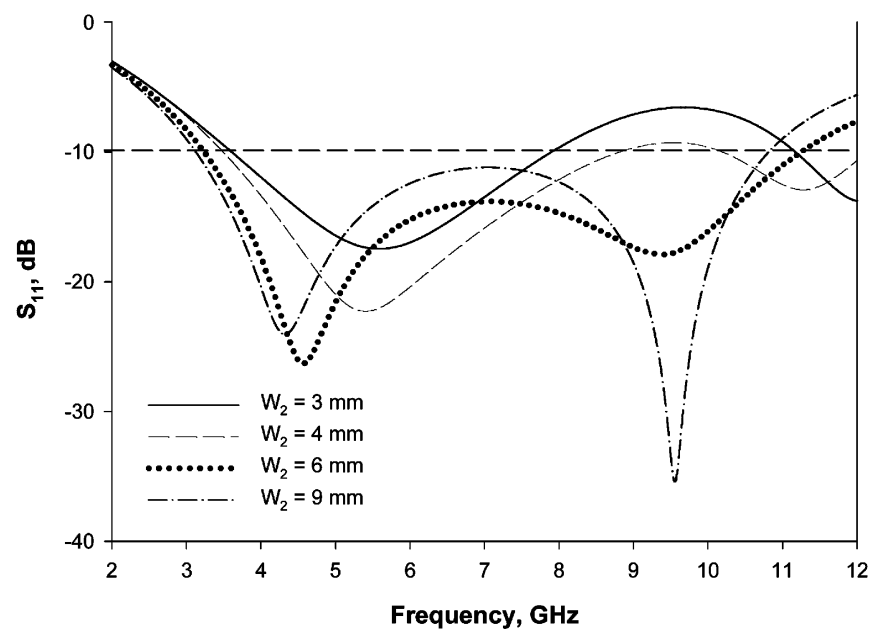

Fig. 4. Simulated return loss for various $W_{2}$ on the truncated ground plane.

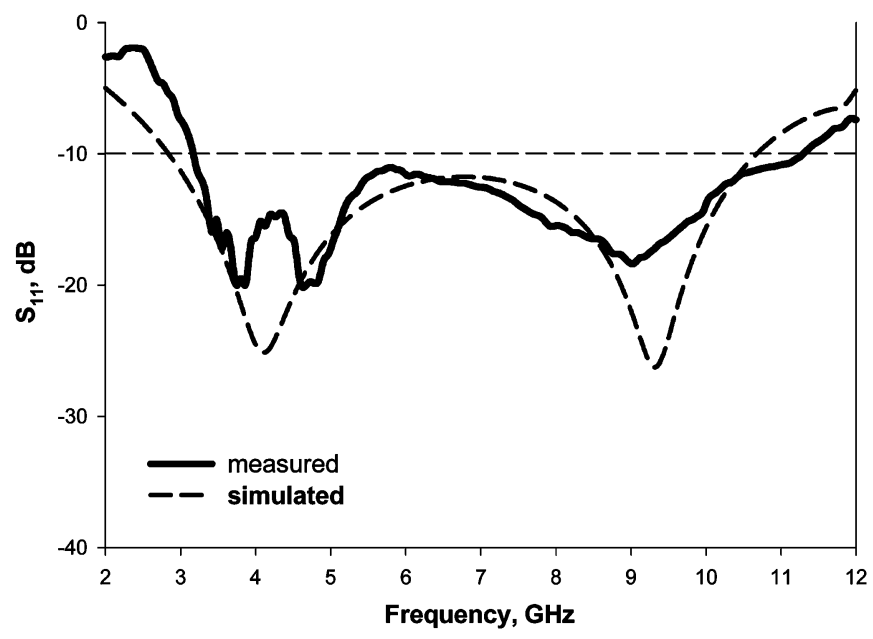

Fig. 5. Measured and simulated return loss characteristics for an optimized microstrip-fed monopole antenna. $\left(W_{\text {sub }}=16 \mathrm{~mm}, L_{\text {sub }}=18 \mathrm{~mm}, W=\right.$ $7 \mathrm{~mm}, L=11 \mathrm{~mm}, W_{1}=1 \mathrm{~mm}, L_{1}=2 \mathrm{~mm}, W_{2}=7 \mathrm{~mm}, L_{2}=1 \mathrm{~mm}$, $L_{3}=3 \mathrm{~mm}, W_{f}=2 \mathrm{~mm}$, and $L_{\mathrm{grd}}=4 \mathrm{~mm}$ ).

satisfies the $10-\mathrm{dB}$ return loss requirement from 3.1 to $11 \mathrm{GHz}$. Measured radiation patterns at 3,6 , and $9 \mathrm{GHz}$ are shown in Fig. 6. Monopole-like radiation patterns in $y-z$ planes 

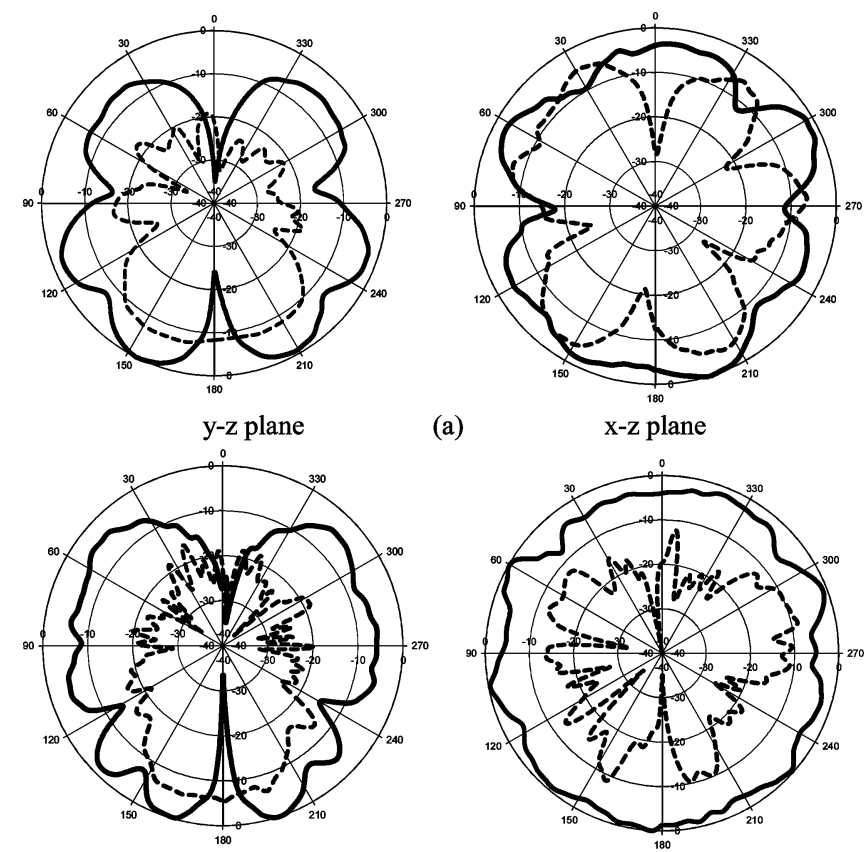

(a)
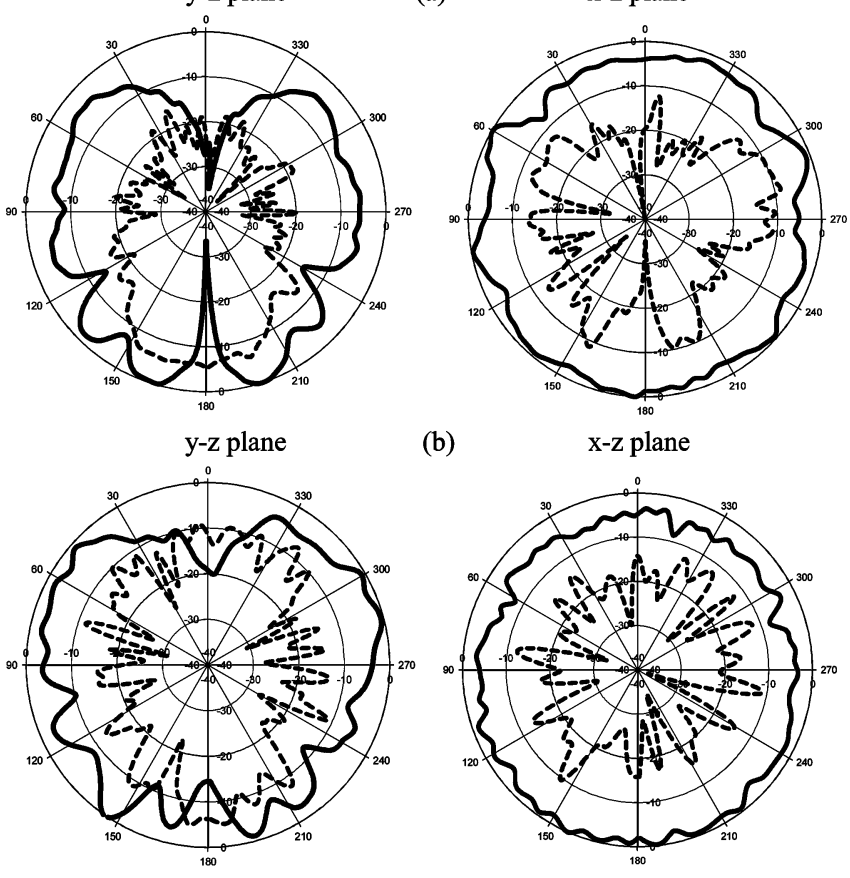

y-z plane

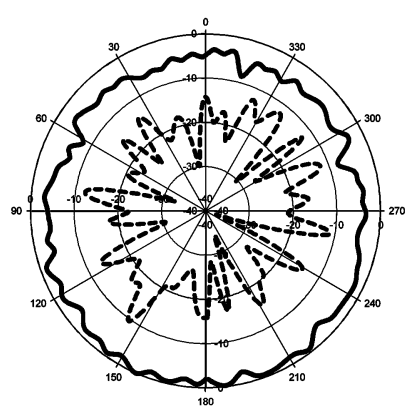

(c)

$\mathrm{x}-\mathrm{z}$ plane

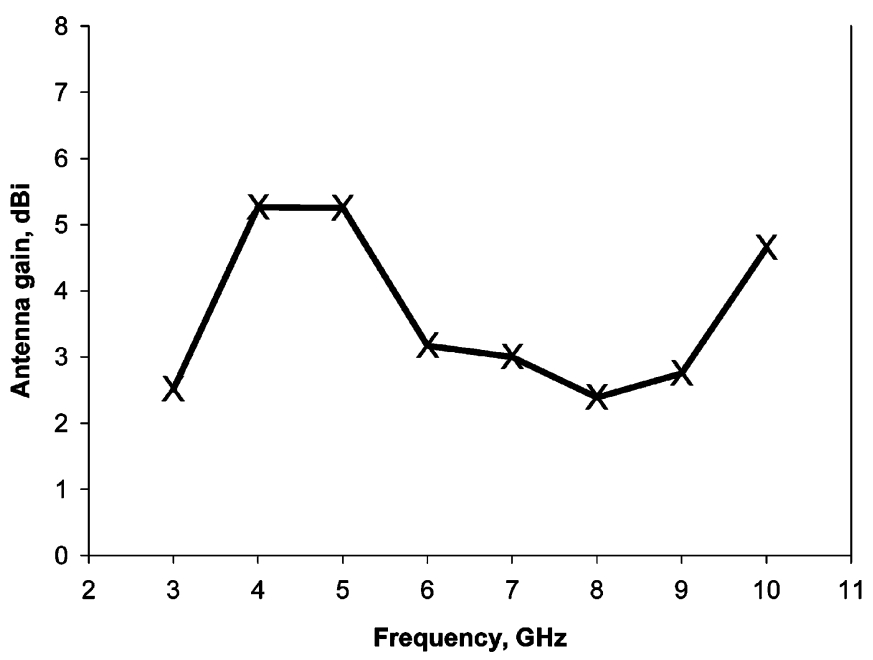

Fig. 7. Measured antenna gain of the proposed antenna.

proposed antenna has a simple configuration and is easy to fabricate. To obtain the wide bandwidth, the sizes of notches at the two lower corners of the patch and notch on the truncated ground plane have been optimized by parametric analysis. The designed antenna satisfies the $10 \mathrm{~dB}$ return loss requirement from 3.1 to $11 \mathrm{GHz}$ and provides good monopole-like radiation patterns. Experimental results show that the proposed antenna could be a good candidate for hand-held UWB application.

\section{REFERENCES}

[1] FCC, "First Report and Order on Ultra-Wideband Technology," Tech. Rep., 2002.

[2] J. Young and L. Peter, "A brief history of GPR fundamentals and applications," in Proc 6th Int Conf. Ground Penetrating Radar, 1996, pp. $5-14$.

[3] D. J. Daniels, "Surface-penetrating radar," Proc. Inst. Elect. Eng., ser. 6, pp. 72-93, 1996.

[4] Z. N. Chen, M. W. Y. Chia, and M. J. Ammann, "Optimization and comparison of broadband monopole,,"," Proc. Inst. Elect. Eng., vol. 150, no. 6, pp. 429-435, Dec. 2003.

Fig. 6. Measured radiation patterns of the proposed antenna. (a) $3 \mathrm{GHz}$. (b) $6 \mathrm{GHz}$. (c) $9 \mathrm{GHz}$.

are observed. The radiation patterns in $x-z$ planes are approximately omnidirectional, especially for the upper operating frequencies. Fig. 7 shows measured antenna gain from 3 to $10 \mathrm{GHz}$ for the proposed antenna. The maximum gain variation is less than $2.8 \mathrm{~dB}$ with the peak antenna gain at about $5.26 \mathrm{dBi}$.

\section{CONCLUSION}

A novel compact microstrip-fed monopole antenna has been proposed and implemented for ultra wideband application. The

[5] N. P. Agrawall, G. Kumar, and K. P. Ray, "Wide-band planar monopole antennas," IEEE Trans. Antennas Propag., vol. 46, no. 2, pp. 294-295, Feb. 1998.

[6] E. Antonino-Daviu, M. Cabedo-Fabre's, M. Ferrando-Bataller, and A Valero-Nogueira, "Wideband double-fed planar monopole antennas," Electron. Lett., vol. 39, no. 23, pp. 1635-1636, Nov. 2003.

[7] S. W. Su, K. L. Wong, and C. L. Tang, "Ultra-wideband square planar monopole antenna for IEEE 802.16a operation in the 2-11 GHz band," Microw. Opt. Technol. Lett., vol. 42, no. 6, pp. 463-466, Sep. 2004

[8] J. P. Lee, S. O. Park, and S. K. Lee, "Bow-tie wideband monopole antenna with the novel impedance-matching technique," Microw. Opt. Technol. Lett., vol. 33, no. 6, pp. 448-452, Jun. 2002.

[9] Ansoft High Frequency Structure Simulation (HFSS), Ver. 9.2, Ansoft Corporation, 2004. 